\title{
ANALISIS KESULITAN SISWA DALAM MENENTUKAN FAKTOR PERKALIAN, KOEFISIEN, KONSTANTA, SUKU, DAN SUKU SEJENIS
}

\author{
Mika Ambarawati \\ IKIP Budi Utomo Malang \\ mikaambarawatio88@gmail.com
}

\begin{abstract}
Abstrak
Artikel ini merupakan hasil penelitian yang bertujuan untuk mendeskripsikan kesulitan belajar siswa dalam mempelajari variabel (peubah), konstanta, koefisien, faktor-faktornya, jenis suku, sukusuku sejenis, dan suku-suku tak sejenis. Jenis penelitian ini adalah penelitian deskriptif dengan pendekatan kualitatif. Jenis penelitian ini adalah penelitian deskriptif dengan pendekatan kualitatif. Subjek dari penelitian ini terdiri dari 3 siswa kelas VII A SMP 1 Muhammadiyah Kartasura. Instrumen yang digunakan adalah lembar soal faktor perkalian, koefisien, konstanta, suku, dan suku sejenis serta lembar wawancara.Teknik analisis data menggunakan konsep Miles dan Huberman. Hasil penelitian menunjukkan: (1) siswa mengalami kesulitan dalam memahami konsep dan definisi tentang jenis suku, faktor perkalian ,suku-suku sejenis atau sukusuku tak sejenis, suku, konstanta, variabel, dan koefisien bentuk aljabar. (2) siswa mengalami kesulitan dalam mengelompokkan bentuk aljabar berdasarkan jenis sukunya. (3) siswa mengalami kesulitan dalam membedakan faktor perkalian bentuk aljabar dan faktor perkalian bilangan. (4) siswa mengalami kesulitan dalam membedakan suku-suku sejenis atau tak sejenis beserta alasannya.(5) siswa kesulitan dalam mengklasifikasikan suku, konstanta, variabel, dan koefisien bentuk aljabar.

Kata Kunci: kesulitan, faktor perkalian, koefisien, konstanta, suku, suku sejenis.
\end{abstract}

\begin{abstract}
The purpose of this study is to describe students' learning difficulties in studying variables, constants, coefficients, the factors, types of parts, similar tribes, and the tribes do not like. This research is a descriptive study with qualitative approach. This research is a descriptive study with qualitative approach. The subject of this study consisted of three students of class VII A SMP Muhammadiyah 1 Kartasura. The instrument used was a booklet multiplication factor, coefficients, constants, parts, and similar parts and pieces of interviews. Data were analyzed using the concept of Miles and Huberman. The results showed: (1) students have difficulties in understanding the concepts and definitions of the types of parts, multiplication factors, the tribes of similar or not similar tribes, tribal, constants, variables, and the coefficient of the algebra. (2) students have difficulty in classifying the algebra by type tribe. (3) students have difficulty in distinguishing factor of the algebra and multiplication factor numbers. (4) students have difficulty in
\end{abstract}


differentiating the tribes of similar or not similar and why. (5) students' difficulties in classifying the tribe, constants, variables, and the coefficient of the algebra.

Keywords: difficulties, multiplication factors, coefficients, constants, tribes, and similar parts.

\section{PENDAHULUAN}

Aljabar merupakan salah satu materi dalam matematika yang mulai diper-kenalkan dalam jenjang pendidikan pada sekolah menengah pertama. Materi aljabar biasanya mulai diajarkan di kelas VII. Standar kompetensi yang harus dikuasai oleh siswa dalam mempelajari aljabar, yaitu memahami bentuk aljabar, persamaan, dan pertidaksamaan linear satu variabel. Tujuan pembelajaran aljabar di tingkat SMP dan sederajat adalah pemahaman konsep. Dengan demikian, pemahaman konsep aljabar akan berpengaruh pada pembelajaran aljabar selanjutnya. Pembelajaran aljabar diawali dengan mengenali tentang bentuk aljabar dan unsurunsurnya yang membahas pengertian variabel (peubah), konstanta, koefisien, faktorfaktornya, jenis suku, suku-suku sejenis, dan suku-suku tak sejenis.

Retno Dewi Tanjungsari dkk (2012) dalam penelitiannya menyatakan kesulitan dalam menggunakan prinsip termasuk didalamnya siswa tidak memahami variabel dan kurangnya penguasaan bentuk-bentuk aljabar. Selain itu, kesulitandalam menggunakan konsep termasuk didalamnya ketidakmampuan untuk mengingat konsep.
2001: $\begin{gathered}\text { Menurut Gagne (Erman, } \\ \text { 33), dalam belajar }\end{gathered}$ matematika ada dua objek yang dapat diperoleh siswa, yaitu objek langsung dan objek tak langsung. Objek langsung terdiri dari fakta, konsep, skill, dan prinsip. Begle dalam Herman Hudojo (2005: 36) menyatakan bahwa sasaran atau objek penelaahan matematika adalah fakta, konsep, operasi, dan prinsip. Adapun dalam mempelajari bentuk aljabar dan unsur-unsurnya diperlukan pemahaman konsep, prinsip, dan definisi. Hal ini disebabkan banyak siswa yang tidak mampu menjawab soal-soal sederhana tentang bentuk aljabar dan unsur-unsurnya.

Berdasarkan
$\begin{aligned} & \text { hersebut, peneliti } \\ & \text { ingin } \\ & \text { mendeskripsikan }\end{aligned}$
kesulitan belajar siswa dalam
mempelajari variabel (peubah),
konstanta, koefisien, faktor-
faktornya, jenis suku, suku-suku
sejenis, dan suku-suku tak sejenis.

\section{METODE PENELITIAN}

Jenis penelitian ini adalah penelitian kualitatif deskriptif. Subjek dari penelitian ini terdiri dari 3 siswa kelas VII A SMP 1 Muhammadiyah Kartasura. Instrumen yang digunakan adalah lembar soal faktor perkalian, koefisien, konstanta, suku, dan suku sejenis serta lembar wawancara. Data 
Ambarawati, Mika

Analisis Kesulitan Siswa dalam Mempelajari Faktor Perkalian, Koefisien, Konstanta, Suku, dan Suku

Sejenis

yang dianalisis adalah hasil dari jawaban siswa dan hasil dari wawancara. Sumber data pada penelitian ini adalah siswa sebagai subjek penelitian. Teknik analisis data menggunakan konsep Miles dan Huberman. Keabsahan data yang digunakan adalah triangulasi data dan menggunakan kecukupan referensi.

\section{HASIL DAN PEMBAHASAN}

1. Analisis pada pemahaman konsep dan definisi

Umumnya, siswa yang mendapat nilai di bawah 60 mereka belum memahami konsep atau definisi dari bentuk aljabar dan unsur-unsurnya secara jelas. Sebagian besar siswa menjawab salah dalam menentukan jenis suku aljabar. Selain itu, mereka juga masih salah dalam menentukan variabel dan faktorfaktornya. Konsep dari bentuk dan unsur-unsur aljabar merupakan suatu hal penting yang harus dikuasai oleh siswa. Konsep merupakan pengetahuan dasar matematika yang harus dikuasai oleh siswa, agar siswa dapat menyelesaikan persoalan matematika dengan baik dan benar. Begitu juga dengan definisi dari bentuk dan unsur-unsur aljabar siswa harus memahaminya. Hal ini agar siswa dapat menyelesaikan permasalahan bentuk aljabar dan unsurunsurnya secara tepat.

2. Analisis kesalahan dalam menentukan jenis suku

1. Lengkapi tabel berikut !

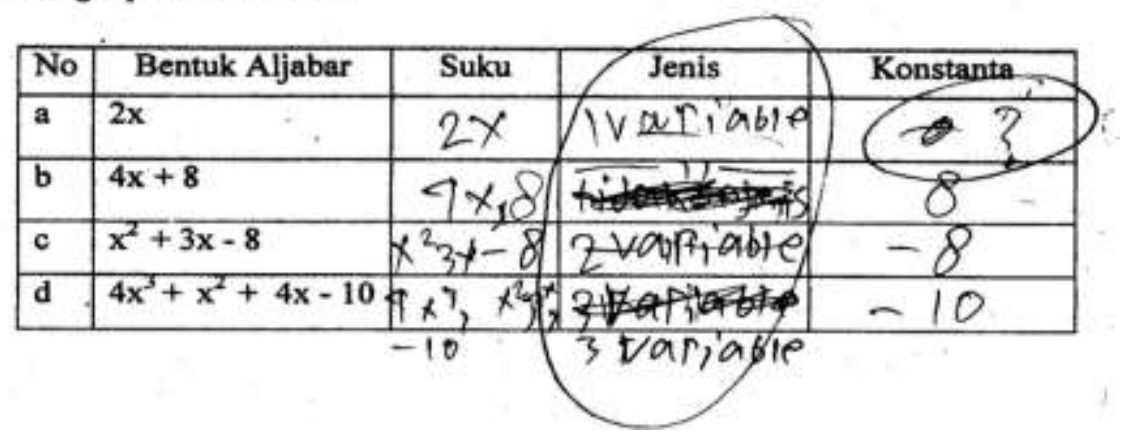

1. Lengkapi tabel berikut !

\begin{tabular}{|l|l|l|l|c|}
\hline No & Bentuk Aljabar & Suku & Jenis & Konstanta \\
\hline a & $2 \mathrm{x}$ & $2 x$ & - & - \\
\hline b & $4 x+8$ & $4 x$ & tiqak sejenis & 8 \\
\hline c & $x^{2}+3 x-8$ & $x^{2} \operatorname{dan} 3 x$ & -11 & 8 \\
\hline d & $4 x^{3}+x^{2}+4 x-10$ & $4 x^{3} \operatorname{don} x^{2}$ & -11 & 10 \\
\hline
\end{tabular}


Siswa dalam menentukan jenis suku banyak diduga adanya kesulitan dalam membedakan jenis suku tersebut. Umumnya, siswa menjawab : (a) $2 x$ (satu variabel), (b) $4 x+8$ (satu variabel), (c) $x^{2}+3 x-8$ (dua variabel), dan (d) $4 x^{3}+x^{2}+4 x-10$ (tiga variabel). Selain itu, beberapa siswa menjawab : (a) $2 x(-)$, (b) $4 x+8$ (tidak sejenis), (c) $x^{2}+3 x-8$ (tidak sejenis), dan (d) $4 x^{3}+x^{2}+4 x-10$ (tidak sejenis). Siswa kurang memahami jenis-jenis suku aljabar terdiri atas, suku tunggal, suku dua, suku tiga, dan suku banyak (polinom). Sebagian besar siswa menjawab salah. Hal ini menunjukkan siswa belum mampu membedakan antara jenis suku tunggal, suku dua, suku tiga, dan suku banyak dari bentuk aljabar.

Bentuk aljabar $2 x$ merupakan suku tunggal bukanlah jenis suku satu variabel karena tidak dihubungkan oleh operasi jumlah atau selisih. Suku satu adalah bentuk aljabar yang tidak dihubungkan oleh operasi jumlah atau selisih. Bentuk aljabar $4 x+8$ merupakan suku dua karena dihubungkan oleh satu operasi jumlah atau selisih bukanlah jenis suku 1 variabel atau suku tidak sejenis. Suku dua adalah bentuk aljabar yang dihubungkan oleh satu operasi jumlah atau selisih. Bentuk aljabar $x^{2}+3 x-8$ merupakan jenis suku tiga karena dihubungkan oleh dua operasi jumlah atau selisih bukanlah jenis suku 2 variabel atau suku tidak sejenis. Suku tiga adalah bentuk aljabar yang dihubungkan oleh dua operasi jumlah atau selisih. Adapun $4 x^{3}+x^{2}+4 x-10$ merupakan suku banyak (polinom) bukanlah suku 3 variabel atau suku tidak sejenis. Hal ini karena bentuk aljabar yang mempunyai lebih dari dua suku disebut suku banyak atau polinom.

3. Analisis kesalahan dalam menentukan faktor perkalian bentuk aljabar

\section{Lengkapi tabel berikut !}

\begin{tabular}{|l|l|c|c|c|}
\hline No & Suku & Variabel (peubah) & Koefisien & Faktor-faktornya \\
\hline a & $8 \mathrm{x}$ & $x$ & 8 & $2,4 x$ \\
\hline b & $-6 y$ & $y$ & -6 & $2,-3 y$ \\
\hline c & $4 x^{2}$ & $x$ & 4 & $2 x$ \\
\hline d & $6 a b x$ & abx & 6 & $2 \times, 3 a b$ \\
\hline
\end{tabular}

Jawaban siswa dalam menentukan faktor perkalian bentuk aljabar menunjukkan adanya kesulitan. Umumnya, siswa menjawab (a) $2,4 x$, (b) $2,-3 y$, (c) $2 x$, (d) $2 x, 3 a b$. Selain itu, juga terdapat beberapa siswa yang tidak menjawab. Hal ini menunjukkan bahwa siswa masih mengalami kesulitan dalam membedakan faktor perkalian bentuk aljabar dengan faktor perkalian pada bilangan.

Soal no $2 \mathrm{a}$ memiliki faktor perkalian $8, x$ dan soal no $2 \mathrm{~b}$ memiliki faktor perkalian $-6, y$. Adapun soal no 2c mempunyai faktor perkalian $4, x^{2}$ 
Ambarawati, Mika

Analisis Kesulitan Siswa dalam Mempelajari Faktor Perkalian, Koefisien, Konstanta, Suku, dan Suku

Sejenis

dan soal no $2 \mathrm{~d}$ mempunyai faktor perkalian $6, a, b, x, 6 a, 6 b, 6 x, 6 a b, 6 a x$, $6 a x, a b x, a b, a x, b x$. Jawaban siswa yang salah menunjukkan siswa belum mampu membedakan faktor perkalian bentuk aljabar dan faktor perkalian pada bilangan. Adapun definisi dari faktor perkalian bentuk aljabar adalah bentuk aljabar yang merupakan bagian dari perkalian.

4. Analisis kesalahan dalam menentukan suku-suku sejenis atau suku-suku tak sejenis beserta alasannya

\section{Lengkapi tabel berikut ( berkaitan suku-suku sejenis atau suku-suku tak sejenis )!}

\begin{tabular}{|c|c|c|c|}
\hline No & Bentuk & $\begin{array}{l}\text { Sejenis/tak } \\
\text { sejenis }\end{array}$ & Alasan \\
\hline a & $2 x$ dan $-6 x$ & Sejenis & (2x) dan-6x) sama \\
\hline b & $5 x^{2}$ dan $4 x$ & sejenis & $(5 x)^{2}$ dan (4x) sama \\
\hline c & $3 a b$ dan $4 a$ & sejonts & (3a) dan (4a) samo \\
\hline d & $5 \mathrm{a}^{2} \mathrm{~b}$ dan $8 \mathrm{ab}^{2}$ & & $\operatorname{dan}\left(8 a b^{2}\right)$ sat \\
\hline
\end{tabular}

Berdasarkan jawaban menunjukkan adanya kesalahan jawaban siswa. Umumnya siswa menjawab, (a) sejenis alasannya $2 x$ dan $-6 x$ sama, (b) sejenis alasannya $5 x$ dan $4 x$ sama, (c) sejenis alasannya $3 a b$ dan $4 a$ sama, (d) sejenis alasannya $5 a^{2} b$ dan $8 a b^{2}$ sama. Selain itu, ada yang menjawab, (a) tidak sejenis alasannya mempunyai sifat asosiatif, (b) sejenis alasannya mempunyai sifat distributif, (c) bukan sejenis alasannya mempunyai sifat komutatif, (d) sejenis alasannya mempunyai sifat komutatif.

Soal no 3a merupakan suku sejenis karena memiliki variabel yang sama $(x)$. soal no 3b merupakan suku yang tak sejenis walaupun variabelnya sama $(x)$ tetapi pangkat variabelnya berbeda. Soal no 3c merupakan suku tak sejenis karena variabelnya yang berbeda ( $a b$ dan $a$ ). Adapun soal 3d merupakan suku tak sejenis pangkat variabel yang berbeda. Berdasarkan jawaban siswa, diduga beberapa siswa belum dapat membedakan antara suku sejenis dan suku tak sejenis.

Siswa seharusnya memahami definisi dari suku-suku sejenis dan suku-suku tak sejenis. Suku-suku sejenis merupakan suku yang mempunyai variabel dan pangkat variabel sama. Adapun suku-suku tak sejenis mempunyai variabel dan pangkat variabel yang berbeda. 
Ambarawati, Mika

Analisis Kesulitan Siswa dalam Mempelajari Faktor Perkalian, Koefisien, Konstanta, Suku, dan Suku Sejenis

5. Analisis kesalahan dalam menentukan suku, kostanta, variabel, dan koefisien

1. Lengkapi tabel berikut !

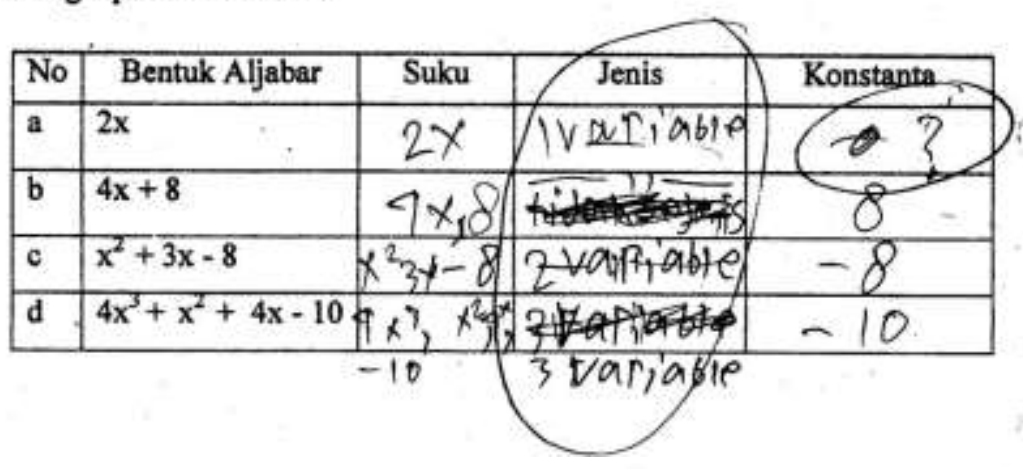

2. Lengkapi tabel berikut!

\begin{tabular}{|l|l|c|c|c|}
\hline No & Suku & Variabel (peubah) & Koefisien & Faktor-faktornya \\
\hline a & $8 \mathrm{x}$ & $\mathrm{x}$ & 8 & $2,4 x$ \\
\hline b & $-6 \mathrm{y}$ & $\mathrm{y}$ & -6 & $2,-3 \mathrm{y}$ \\
\hline c & $4 \mathrm{x}^{2}$ & $\mathrm{x}$ & 4 & $2 x$ \\
\hline d & $6 \mathrm{ab} \mathrm{x}$ & $\mathrm{abx}$ & 6 & $2 x, 3 \mathrm{ab}$ \\
\hline
\end{tabular}

Berdasarkan jawaban di atas diketahui bahwa beberapa siswa belum dapat mengklasifikasikan suku, konstanta, variabel, dan koefisien dari bentuk aljabar. Apabila ditinjau dari definisinya suku, konstanta, variabel, dan koefisien dapat dipahami secara mudah dan sederhana.

Soal no 1 a memiliki suku $2 x$ dengan kostanta (-). Soal no $1 \mathrm{~b}$ memiliki suku $4 x$, 8 dengan konstanta 8. Soal no $1 \mathrm{c}$ mempunyai suku $x^{2}, 3 x$, 8 dengan konstanta -8. Adapun soal no $1 \mathrm{~d}$ memiliki suku $4 x^{3}, x^{2}, 4 x,-10$ dengan konstanta -10 . Siswa yang menjawab salah belum dapat mengklasifikasikan suku dan konstanta dari bentuk aljabar.Apabila ditinjau dari definisi suku adalah variabel beserta koefisiennya atau konstanta pada bentuk aljabar yang dipisahkan oleh operasi jumlah atau selisih. Adapunsuku dari suatu bentuk

aljabar yang berupa bilangan dan tidak memuat variabel disebut konstanta.

Sementara itu, soal no $2 a$ memiliki variabel $x$ dengan koefisien 8. Soal no $2 b$ memiliki variabel $y$ dengan koefisien -6. Soal no 2c memiliki variabel $x$ dengan koefisien 4. Selain itu, soal no $2 \mathrm{~d}$ memiliki variabel $x$ dengan koefisien 6 . Siswa mengalami kesulitan dalam mengklasifikasikan variabel dan koefisiendari bentuk aljabar. Apabila ditinjau dari definisinya, koefisien pada bentuk aljabar adalah faktor konstanta dari suatu suku pada bentuk aljabar. Adapun variabel adalah lambing pengganti suatu bilangan yang belum diketahui nilai dengan jelas. Variabel dilambangkan 
Ambarawati, Mika

Analisis Kesulitan Siswa dalam Mempelajari Faktor Perkalian, Koefisien, Konstanta, Suku, dan Suku

Sejenis

dengan huruf $a, b, c, \ldots .$. dan disebut juga peubah.

\section{KESIMPULAN DAN SARAN}

Kesulitan yang dialami siswa adalah :

1. Siswa mengalami kesulitan dalam memahami konsep dan definisi tentang jenis suku, faktor perkalian ,suku-suku sejenis atau suku-suku tak sejenis, suku, konstanta, variabel, dan koefisien bentuk aljabar.

2. Siswa mengalami kesulitan dalam mengelompokkan bentuk aljabar berdasarkan jenis sukunya.

3. Siswa mengalami kesulitan dalam membedakan faktor perkalian bentuk aljabar dan faktor perkalian bilangan.

4. Siswa mengalami kesulitan dalam membedakan suku-suku sejenis atau tak sejenis beserta alasannya.

5. Siswa kesulitan dalam mengklasifikasikan suku, konstanta, variabel, dan koefisien bentuk aljabar.

Saran-saran yang dapat dikemukakan berdasarkan hasil penelitian ini yaitu: (1) Siswa harus mempelajari konsep dan definisi jenis suku, faktor perkalian, suku-suku sejenis, suku, konstanta, variabel, dan koefisien secara menyeluruh dengan menggunakan pembelajaran yang konstektual; (2) Siswa harus memahami konsep dan definisi dari jenis suku bentuk aljabar. Selain itu, memperhatikan perbedaan antara jenis suku tersebut dan banyak berlatih mengerjakan soal. Selain itu, memberikan contoh dari permasalahan konstektual; (3) Siswa harus banyak berlatih soal dalam menentukan faktor perkalian dengan jenis suku bentuk aljabar yang berbeda. Selanjutnya, dapat dilihat perbedaan faktor perkaliannya. Selain itu, dapat menggunakan model pembelajaran yang dapat diterapkan dalam materi ini; (4) Siswa harus mempelajari definisi dan konsep perbedaan suku-suku sejenis dan suku-suku tak sejenis. Dengan berlatih mengelompokkan soal-soal ke dalam suku-suku sejenis dan sukusuku tak sejenis maka dapat menjelaskan alasannya. Selain itu, memberikan contoh dari permasalahan konstektual; (5) Siswa harus banyak berlatih soal-soal dalam menentukan suku, kostanta, variabel, dan koefisien. Menggunakan pembelajaran konstektual dalam mempelajari materi ini. Selain itu, dalam proses pengerjaan soal siswa harus lebih teliti dan cermat sehingga dapat mengerjakannya dengan benar.

\section{DAFTAR PUSTAKA}

Suherman, E, dkk. 2001. Strategi Belajar Mengajar Kotemporer. Bandung: Depdikbud.

Hudojo, H. 2005. Pengembangan Kurikulum dan Pembelajaran Matematika. Malang: UM Press.

Tanjungsari, R. D., Sudjoko, E., \& Masyuri. 2012. Diagnosis Kesulitan Matematika SMP Pada Materi Persamaan Garis Lurus. Unnes Journal Mathematics Education, 1 (1). 56-57. 